\title{
Intuition and Technological Artifice: The Interplay of Their Importance
}

\author{
Theodore John Rivers \\ John Adams High School, New York, USA
}

Email address:

trivers13@verizon.net

\section{To cite this article:}

Theodore John Rivers. Intuition and Technological Artifice: The Interplay of Their Importance. Science, Technology \& Public Policy. Vol. 4, No. 2, 2020, pp. 60-68. doi: 10.11648/j.stpp.20200402.13

Received: March 10, 2020; Accepted: July 20, 2020; Published: July 28, 2020

\begin{abstract}
The simple or elementary meanings of intuition and technological artifice are not so simple or elementary when they are joined together. Nevertheless, their combined importance helps to explain how free choice underscores creativity. In reference to intuition, emphasis is placed upon the concentration of mental powers, and in reference to technological artifice, emphasis is placed upon an ability that facilitates invention. Technological artifice is open-ended and may serve any cause, but regardless of its means, it remains an uncertainty. The interplay between intuition and technological artifice is expressed by the intuitive ability to observe something closely or to manifest a concentration of mental powers, but also the ability to invent or innovate. The thought of thinkers from Aristotle to the present are discussed indicating that intuition is always dependent upon the world and does not precede it. Although invention and its modification by means of innovation require technological artifice, the latter is not and will never be self-contained. Intuition remains a necessity in order for technological artifice to operate, as it confirms that consciousness in general is distinct from self-consciousness, and yet is coexistent with it. When expressed in metaphysical terms, non-being (that which does not exist) is the source where reality originates, including technological artifice. The revealing of being from non-being occurs through the act of becoming in which being is manifested from non-being. Technological artifice is the result of this becoming.
\end{abstract}

Keywords: Intuition, Technological Artifice, Becoming

\section{Introduction}

It may seem peculiar to link intuition with technological artifice, as these terms are usually understood. Nevertheless, this peculiarity is pertinent even when we consider that intuition is an apprehension that concerns human behavior, whereas technological artifice, rightly or wrongly, is usually associated with the methodologies of technology's underlying procedures and practices. Though seemingly different, intuition and technological artifice are expressive of a relationship that is similar to a relationship in mathematics, in which two points share a continuous path, rendering them coherent. And the coherence of intuition and technological artifice concerns how the latter acquires meaning because of the intuitive ability to build upon human experience. It is important for us to draw attention to this relationship because it indicates where technological artifice originates. Although our inquiry could point us in many different directions, we need to direct our attention instead to a few key points that emphasize what is important for technological artifice to appear and be applied. Ultimately, our concern is not so much a clarification of intuition, which has wide applications in many disciplines and has received the attention of numerous writers, but with technological artifice.

We should also mention that this paper is not supportive of experimental philosophy and its view that intuition has nothing (or very little) to do with philosophical arguments, an interpretation that should remind us that just as any theory that makes predictions in opposition to reasonable and fair observations will lack credibility, so too any topic without referencing previous thinkers is similarly positioned. Surely, it is rare for anything to originate in a vacuum, as it is also rare that we can understand the latest version of anything without referring to its former. We should conclude, therefore, that philosophy or any discipline should not exclude its own history.

What became "intuition" in the English language as 
derived from its Latin roots allowed for simple, but pointed meanings, revealing a word with fundamental characteristics. Intuition in modern English is derived from late middle English (appearing in the 15th century) from the late medieval Latin intuitio, which itself is based upon the past participle of intueri (to look at attentively or to gaze at). Hence, intuition is the ability to bring close observation to something, to express watchfulness, to manifest the concentration of mental powers, or to look intently or steadily upon something. To know something intuitively is to know it directly.

Similarly, what became "artifice" in the English language is also derived from late middle English (appearing in the $16^{\text {th }}$ century) from middle French artifice, which itself is based upon Latin artificium (a profession or craft, or the act of making something by art, or a system of art formulated, particularly as a method) from artifex (craftsman). Artifex in turn is composed of Latin ars (art) and facere (to do or to make). Although artifice also means cunning or trickery, in our sense it means artful or skillful craftsmanship, which is the ability to devise or invent something that is hopefully followed by innovation. Synonyms of artifice include artfulness, skill, artistry, cleverness, adeptness, masterfulness, or skillfulness. Artifice signifies an upsurge of energy and creative power that springs forth from an openness to being. It is a precondition to a creation as an artist is a prerequisite for a painting.

Apart from this general understanding of artifice, there appears to be some confusion regarding its etymological derivation when artifice is compared with artifact. Artifice and artifact have the same Latin roots, that is, ars (art) and facere (to do or to make), which makes them derivatively similar, but it is a misunderstanding to associate artifice as artful or skillful craftsmanship with artifact as an object. Since artifice is associated with an idea or concept, it cannot also be associated with its result, such as an artifact. Because artifice is not natural, it can be understood as an artificiality, but first it must be associated with the process of thinking. If artifice is the description of a concept that may be thought to be materialized into a praxis, we should conclude that to equate artifice as artifact is to equate the embodiment of an idea with the idea itself; but there is a world of difference between an idea and its externalization. Artifice signifies the ability, innate quality, or potency to do, achieve, or affect something, but not the thing, object, or artifact as the recipient of doing, achieving, or affecting. It remains a mental or nonphysical cause of a consequence. Furthermore, there is also confusion between what is abstract and what is concrete. Artifice is an abstraction, although applicable as an idea, whereas an artifact is concrete because it is made of some material substance. The abstraction of one is confused with the concretization of the other. Nevertheless, we should conclude that an artifice is not an artifact. [1]

\section{Intuition}

Beginning our analysis with intuition, we can say that the
Latin derivation of this term indicates a wide range of applications when referring to the faculty of sensation, notably with the capacity to understand or become aware of something, or the ability to determine the importance of it. As a result, we may conclude that we have many intuitive senses. For example, there is an intuitive sense of time, space, and numbers as a fundamental way of understanding the world; an intuitive sense of human behavior that relates to the daily give and take of life, socially or communally; an intuitive sense of fairness that impacts the exchange of goods and services that may be deemed unfair when some people are given preferential treatment; an intuitive sense of belief in the existence of things outside the material or natural world that supports the idea of supernatural powers; an intuitive sense of nature and how the natural environment functions; an intuitive sense of purpose that encourages the attainment of goals; an intuitive sense expressed psychologically, such as the desire for pleasure and the avoidance of pain; an intuitive sense of location as a primitive form of cartography; an intuitive sense of curiosity that occurs naturally to people; an intuitive sense of formulating and manipulating objects as a simple form of engineering, and there are many other intuitive senses as well.

Regardless how intuition is understood, it must be concluded that any mental faculty does not necessarily have to be a reasoning faculty. If intuition, as a type of mental faculty, is thought to be a form of reasoning, then it must be discursive, which means that a conclusion is reachable by means of reason. Although such a conclusion may be inferred, it is antithetical to how intuition functions, as specified above by its many intuitive senses. In reference to the meaning of discursive, we do not mean passing from one subject to another (rambling) or an expression of speech, but a type of reasoning without any intuitive input. If intuition is the result of general principles or assumptions about what ought to be, then its reasoning is deductive. If, on the other hand, it is the result of building upon particular or individual facts, then its reasoning is inductive. But neither conclusion is true because reason is not fundamental to intuition, and must follow and not precede its occurrence.

It should be noted that we are concerned with intuition not in the sense of understanding something based on propositions of the truth of that thing (its object), but in the sense in which something seems true based on inference (from that object). Unfortunately, inference implies not only deriving logical conclusions from premises thought to be true, but inference also implies what is known to be true, which indicates that intuition is an ambiguous term. If anything, we must assume the broadest interpretation of intuition possible.

Although there is much agreement that intuition is a means of acquiring knowledge, there is less agreement that intuition is based on reason, since there is nothing rational about intuitive insightfulness. And as a means of acquiring knowledge, intuition is acceptable by itself without combining it with anything else. Reason may later be attached to it, but its inclusion is merely supplemental to the presence of intuitiveness. Intuition and reason cannot initially 
be combined because the former is phenomenological, but the latter is epistemological.

The importance of intuition has attracted the attention of many philosophical thinkers, beginning fundamentally with Aristotle who described intuition as a type of knowledge that was divorced from any type of reasoning, especially discursive. Considered to be the most important type of knowledge, intuition is necessary in order to understand reality because it confers a clear assessment of universals, an understanding that is achieved through the senses. Universals (the basis of general concepts) became the intended goal of intuition that made objects intelligible. For Aristotle, sense experience did not create universals, but merely revealed their existence. Intuition was a form of knowledge, but not a form of thinking. [2]

However, Aristotle's separation of intuition from discursive reasoning was not accepted by later philosophers, most notably by Descartes, whose main preoccupation, in addition to analytic geometry, was verifying the proof of existence. Thus, in order to arrive at certainty when confronted with doubt, Descartes disregarded whatever could be gleamed from the senses, and limited the proof of existence to thinking about it. Mental existence was presumed to be affirmed, but physical existence was not. [3] Descartes extended this thought with an inference to intuition which he joined with reason, [4] concluding that knowledge of mental existence is intuitive because it required no proof, since it is self-evident. Intuition for Descartes served to confirm existence. In addition to thinking and the use of intuition, Descartes stressed that attributes or qualities of an existent reinforce the proof of existence. Unfortunately, what results from this philosophy is a tautology, that is, existence confirms intuition because intuition verifies existence. Such a conclusion renders not only the body, but also the world as irrelevant.

In the second half of the eighteenth century and slightly more than a century after Descartes, original insights into the notion of intuition were proposed by Kant, but his insights rendered intuition more obscure, especially in reference to his understanding of space and time. Rather than emphasizing if space and time have reality independent of intuition, we should emphasize instead the intuitive relationship that seems to exist because of our awareness of them. The issue of the reality of space and time, whether or not they are or are not independent of intuition (important to Berkeley, Leibniz, and Kant), is an entirely different issue. To say that we have an intuitive sense of space and time, and that this sense is subjectively applied, is not to say that they are not objective. Even if space and time were not attributes of objects, but were the result of how we view them, their importance would not be diminished, and it is this importance that is emphasized in this paper.

Not only did Kant separate sensation from intuition, but he also introduced the idea that we have non-empirical (or a priori) intuition, [5] which is the result of the alleged separation of sensation from intuition. Regardless of how we position apriority with intuition, whatever relationship they have concerns objects. In reference to the former, there must be an absence of sense experience for a priori to be prior, and in reference to the latter, there must be a presence of some "object" in order for it to be intuited. It seems impossible to have it both ways, that is, to have a priori intuition, and intuition that incidentally is a posteriori. A posteriori intuition concerns the world experientially or phenomenologically, and a priori intuition concerns the world non-experientially or conceptually. [6]

This Kantian notion of apriority also influenced the idea of philosophical intuition that is considered to be a special type of intuition because it is based on the understanding that a proposition is true because it is understood to be true, but the understanding of the truth of mathematics, for example, as one type of a priori should not be confused with the reflective introspection associated with understanding that might be intuited by anyone. It might seem harsh to say that philosophical intuition is not epistemologically helpful, but it may be fair to say so. This elevated notion of philosophical intuition as being superior to the common or ordinary notion is an exaggeration and a distortion.

Some of these arguments were expanded by Bergson in the late nineteenth and early twentieth centuries who introduced his own understanding of intuition and its meaning to human reality. Apart from his attempt to correct Kant's notion of absolute knowledge, Bergson introduced original ideas into the notion of intuition and how these ideas relate to science. Since any assessment of reality may be inaccurate, intuition in itself becomes meaningful because it allowed for an interpretation (or adaptation) of the real. It is not only continual with phenomena of the world, but it is also continuous. But more than this, intuition forms an undivided continuity (continuité indivisée) with the reality it encounters. [7] Nevertheless, Bergson attempted to equate intuition with instinct. Although it is difficult to determine how far intuition can be applied, it certainly should not be debased or transformed into instinct, which Bergson attempted. [8] We should ask in what sense can intuition limit itself or reduce itself to instinct. We should also ask how instinct impacts free and ontologically independent individuals. If intuition may be described as memory, then it cannot be equated with perception. The lack of perception contradicts the meaning of intuition and becomes counterintuitive.

The continued analysis of intuition is also evident in the thought of Husserl who accepted the commonly held understanding of intuition as a way for direct inspection of something when it is not influenced by anything else, [9]a thought which implies that whatever presents itself must be accepted as a source of knowledge. But Husserl also believed that we can understand the essence of something if we set aside or bracket the non-essential qualities of that thing. The phrase he used to help us understand the essence of something he called essential or eidetic intuition which means that we are able to understand the essence of something by perceiving it directly. [10] Therefore, there are two, but related types of intuition: perceptive and eidetic, that is, intuition caused by seeing something, and intuition caused 
by insight into the essence of something. Of these two types, eidetic intuition was considered by Husserl to be more fundamental, and yet it cannot reveal anything factual about the thing whose essence is supposedly revealed. Equally important is the view that intuition does not have to be grounded in sensory experience. After intuition has been used, it may be in need of rational support to affirm its conclusion, or to correct one that is incorrect or suspect. At this point, rational argument is used to affirm what intuition has uncovered, but regardless of the impression that intuition gives, it is vital for understanding the world.

Not only is intuition vital for understanding the world, but Sartre would add that all knowledge is intuitive because intuition signifies the existence of consciousness that we are conscious of which in turn forms the basis of knowledge. Although consciousness reveals being, it is not being. In order for this to take place. a dichotomy occurs between unconscious being (described by Sartre as être-en-soi or being-in-itself) and conscious being (described as être-poursoi or being-for-itself). This dichotomy between unconscious and conscious being is described as nothingness, which gives support to being, but is not being. Although nothingness indicates what unconscious being desires, it also reveals what the conscious being achieves. Nothingness is expressed as a negativity because it is expressive of what we did not attain. Being-in-itself and being-for-itself are inseparable, since the latter contains the former. Being-for-itself reveals the negation we create and express in our consciousness, as expressed for example in the regret we feel because we did not fulfill our goals. Since being-for-itself is self-conscious being, it is consciousness expressed phenomenologically, and phenomenology is the key to Sartre's ontology.

For Sartre, intuition is directly influenced by consciousness, and if perchance it lacks a relationship, then intuition would have no importance. This relationship may be expressed in the following way: to be conscious of something must be related to and distinguished from the consciousness that results from that thing receiving the attention of consciousness. Being-for-itself is reinforced by intuition, but like consciousness, it must be separated from its object. Consciousness is aware of its object that is disjoined from the reality to which it is connected. Hence, all knowledge with its corresponding connection is intuitive. [11]

Without going too far afield, we should note that there is a common element among all these thinkers, although they emphasize different subordinate ideas within the general theme of intuition. Typical of ancient Greek thinkers, Aristotle concluded that intuition is a form of knowledge referencing an objective world that leads to an understanding of universals, a major preoccupation of ancient metaphysics. Descartes presumed that intuition confirmed proof of human existence without the necessity of the senses in verifying it. Similarly, Kant emphasized the separation of intuition from sensation, but unlike Descartes, he was preoccupied by the dichotomy between a priori and a posteriori knowledge. In the pursuit of absolute knowledge, Kant uncovered, but did not resolve, the innate contradiction of sensory and non- sensory intuition. Nor was this problem resolved by Bergson who eliminated perception as the principal component of intuition and reduced it to instinct. Comparatively, Husserl assumed that the essence of anything can be known by a simple intuitive analysis that does not have to be based upon the senses. As a result, the thought of Descartes, Kant, and Husserl suppressed the relationship between intuition as a way of knowledge and sensory experience. Their thought was the opposite of Sartre's interpretation that illustrates not only the struggle between the desire of human choices and their realization, but also our complete dependence on intuition in order to verify consciousness that serves as the foundation for all knowledge.

As we noted above, many thinkers emphasized different ideas within the general theme of intuition, but the most common idea among them concerned sensation and its relationship to human experience. An affirmation of sense experience verifies its importance in applying and understanding intuition, but even its denial is indicative of its recognition because first there must be an acknowledgment of what is, that then is followed by a denial that purports what cannot be. A denial is a statement or position that something is not accepted as true, and what is not accepted as true must recognize the existence of an idea denied. Hence, sense experience in reference to intuition is a commonality among all thinkers, both for those who affirm its importance and those who deny it.

The senses impact the understanding of intuition, but the senses and intuition are not identical, that is, the senses are not intuitive, and intuition is not sensory. They overlap, but they are not the same thing. Intuition cannot function without the senses because the senses are needed in order for the intuitive person to become aware. If intuition is presumed to be antecedent to experience and concomitant with being, then it might be presumed to be a priori, but such a conclusion cannot precede birth. We cannot prove that intuition exists in the fetus within the womb, but we can assume that it begins when the human baby is born and develops as the child develops, maturing at a fairly early age.

The goal of the application of the senses is the empowerment of the intuitive person, but the senses lack importance unless they enable the intuitive person to become aware of things (objects, subjects, forces, appearances) that abound. Intuition is positioned between the self as an entity and the world as another. Intuition's response to an object is immediate since it is the nature of intuition to act and react simultaneously when presented with something. It is a posteriori, not a priori. [12] Because it lacks an intervening agency, it remains an intermediary that enables the self to engage with what is presented to it, as the intuitive senses described above indicate. If intuition means more than introspection and more than self-examination, then this condition is the result of its dependency upon the world with which it is connected. Like the self from which it originates, intuition needs the world. There is no intuition without the self that contains it and without the world that supports it, thereby rendering intuition dependent upon the world's 
existence.

Without sensory experience, intuition logically cannot be said to have any, but it also cannot be said that it lacks the ability to acquire it. When we think of intuition, we are not necessarily concerned about its first occasion, but subsequent occasions, because intuition is demonstrative of a stream of self-consciousness. Since everything begins somewhere at some time, emphasis should be placed upon what an existent is which presupposes how it became, an understanding that is meaningful to all things. And because we are human, this reasoning is pertinent to how intuition relates to becoming. It is conceivable not to stress the importance of experience in reference to intuition, but because intuition cannot function without the senses, it would be contradictory to do so. Therefore, to whatever degree, experience is essential to intuition, but it is not helpful to describe intuition as instinct or hidden intelligence. Intuition is atoned to existence because it is a means that aids in the becoming of being.

Nevertheless, intuition is meaningless without underlying motives. Although a motive is a reason for doing something, it is not a cause for it. A motive cannot be identified until after its result occurs, which is similar to how a detective investigates a crime, but a cause can be identified before its result occurs. Reasons and causes impact results, but they are not comparable. Actions are performed because of motives, but the latter are neither conditional nor contingent. But neither are they existent. A motive merely explains an action, but it is not antecedent to it.

Accordingly, there should be no stretch of the imagination to connect feeling with intuition as there should be no stretch of the imagination to connect feeling with technological artifice. Since feeling relates to becoming, it must also relate to technological artifice because the latter is equally ontological. Feeling is tied to an openness of being, to free choice, to uncertainty and opportunity, all of which give a foundation to technological artifice, indicating its ontological or non-technical underpinning.

\section{Technological Artifice}

Technological artifice is the second term we will analyze, but any difficulty in defining it is related, in part, with the difficulty in defining technology, to which it is connected. And the difficulty in defining technology concerns not only what it includes, but also where it originates. Certainly, society must be included in a definition of technology, and once we admit that society is a type of technology in its own right, anything that relates to it is magnified. For even the designation of "technological society" as a particular type of society should encourage us to analyze society in general as a technology that then becomes more technological when it is transformed into a "technological society." Therein is one of the problems of understanding technology because it does not have a limited, but an all-encompassing perspective. Technology is more than tools, machines, and devices. It includes every aspect of human reality that influences human behavior in concert with technology and a technologically dominant culture. This inclusivity is relevant culturally and socially, regardless of how it is expressed. Therefore, an accurate definition of technology and its artifice allows for the relevancy of the latter with human behavior, and for our present concern, with intuition as well. Because technological artifice exemplifies self-reflection, it is connected intuitively with ourselves. It is a reflection of selfconsciousness, joined with the being of being human. It is connected with a deeply directed humanly based condition that helps to determine human reality in relationship with the world, a reality that is subject to an interpretive stance influenced by and conditioned to everything we have been and will ever be.

Intuition is imaginative because it is abstracted, and technological artifice is similarly characterized. Although both intuition and technological artifice may be considered apart from the reality they represent, this similarity cannot be extended to the relationship between technology and technological artifice because although technology and technological artifice are related, they are not equivalent. And they are related because there is a component of free choice that underlies both. In its totality, technology cannot be understood intuitively because it is not characterized by abstraction, detachment, or manipulation. [13]

Initially, technological artifice has been compared to a type of method that offers an approach to activity that may be repeatable in some way while remaining subject to change. It must be inventive because it is the result of a burst of energy that may lead somewhere, or if unsuccessful, nowhere. Knowing that artifice means artful or skillful craftsmanship as the basis for creativity does not mean or imply that it originally is a structure that must be copied and adapted by others. Rather, artifice means the scheme or program singularly brought into being by an individual. It may be imitated by others, but it originates individually.

Technological artifice does not guarantee that it constitutes all of the actions associated with it, nor does it guarantee that every approach to it, like intuition, is rational. There is no guarantee that an artifice will always confer a sense of order, although it may be assumed that it allows us to bring order out of chaos. Theoretically, it may confer this sense; practically, it may not. Even applying an artifice faithfully does not guarantee its success.

Nevertheless, the relationship between technological artifice and reason is ill-defined because the initial establishment of artifice may conflict at a later time with its applications. Therefore, technological artifice may initially be subject to reason because we are rational, but it is not necessarily followed by it. A natural affinity to doing something well, such as excelling in the performance of a sport, may have greater importance to technological artifice than its compliance with reason. When it is methodic, technological artifice is subject to conditions commonly associated with methods in general. When not methodic, technological artifice is subject to the possibility that something will happen, giving support to chance, opportunity, likelihood, or risk. Examples that come immediately to mind 
are the harnessing of fire, the invention of the wheel, and the brewing of beer. Technological artifice offers a range of possibilities that are temporal and transient. It does not eliminate free choice nor can it eliminate the anguish we feel-like many other options - because we dislike its result. Because chance refers to activity that may not be predicted or controlled, it is often given support by ingenuity.

Even software models that are presumed to be derived from algorithms (definable as a method, formula, or program that is used to solve problems or achieve goals with the use of a computer) must in some way be intuitively based; otherwise, they could not function. Social media algorithms that reinforce an individual's beliefs when compared with another's also reduce or eliminate conflicting beliefs. Whether intentional or not, polarization of different beliefs may result in promoting an illusionary reality for some individuals and an alienated reality for others.

Technological artifice is influential and transformative, but even when it is not thought out completely, it is still applicable. It may be compared to a system that is supported by a structure, but it is pointless to ask what comes first, system or structure, because both appear simultaneously as do mode and manifestation. Rather than separating one from the other, technological artifice is structurally relevant because it is joined to a system that supposedly gives it support. In a sense, a technological artifice, like a method, does not provide a manner already devised for activity, but simply the means to devise a way to do so. [14] It is openended and may serve any cause. Because it is projected to an end, it must make use of means in order to attain it, but it includes uncertainty. As stated above, it is the ability to devise or invent something. What relates and what does not relate to technological artifice must be, and will be, decided by factors other than itself. The development of artifice, like the development of a method, technique, or skill, reveals human ability in relationship to human capability. We invent, innovate, manipulate, devise, and forge our unconscious desires into conscious renderings, some good and some bad. Sartre's understanding of unconscious and conscious being, as described above, is especially relevant here. New desires produce new results. Although the world changes while human choices in themselves remain basically the same, this condition between who we are and how we act substantiates human reality. Human beings, consciously motivated and self-defined, are strengthened and affirmed by intuition, but intuition itself must be separated from the phenomena or objects that it encounters.

Not existing as a set mechanism nor formulated to regulate human behavior, technological artifice is a template when we choose to devise or make something. Because it cannot exist without the means that apply to it, it may be described as the result of skillful manipulation that is tied to knowledge acquired through human experience. [15] Although technological artifice is essential in order to understand technology, it is more fundamental than any theory or paradigm. Seemingly easy to understand, it remains confusing. Since artifice is an artificiality, it is often considered to be the equivalent of art, particularly in reference to the fine arts whose technical skills are taught in art schools. Because artifice is associated with art, it is artful, and since it is artful, it is artificial. Hence, art, artifice, and artificiality may not be equivalent, but they are connected conjunctively because they share a concurrence. They may be joined together, however imperfectly, because they originate from the same fountain of creativity so commonly associated with ontological freedom. Even when technological artifice is perceived to be socially or politically based, this understanding does not displace its individual origination. Although there are technologies that are applicable in the public sphere, they do not originate there, regardless of how much they seem to be. All human decisions are individual, and all human choices are personal, even when we act in groups.

Technological artifice is an open-ended activity that is unknown until brought into being by our will. It is not determined by technical attributes, but by the choices made by ontologically free beings. What we have just said may give the impression that artifice is a skill that results from planning or formulating separate or particular aspects or phases for the completion of a task. In a sense, it is this, but in another sense, it is not. Technological artifice is more than a description of a skill, although it seems to be so. Rather, it is a description of human life itself that has surrendered itself completely to technology in all its manifestations. Surrender has been transformed into artifice that seeks control of whatever presents itself. Like creativity, surrender symbolizes engagement and supplements the fact that technology by its very nature brings artifice into the world, an artifice that is supported by intuitive insightfulness that gives a conscious perception of conditions bound by experience. Intuition is positioned between the self and the world. It is an intermediary that empowers the self to engage with whatever is presented to it. Hence, technological artifice is the result of apperception, the result of relating past experience to a newly observed object, subject, or thing. [16]

\section{Conclusion}

Intuition is an essential component of humanity's mental capability. It is a trait that is fundamental for a person's interaction as a platform for self-awareness. But to define intuition as the ability to facilitate the assessment of reality that later impacts a person does not mean that it is a type of knowledge as knowledge is typically defined as the means of evaluating and explaining what is, nor should it be confused with some type of Bergsonian "hidden intelligence."

Neither does degrading something to mere subjectivism help to explain the role that intuition plays in human consciousness. To view an object as an embodiment of a knowing subject does not explain reality when there are objects that cannot be explained. If a person is the only way for any object to be known, then indeed it would follow that people are essential for knowing anything. However, such a position cannot be upheld because it not only presents an 
extreme view of reality, apart from anthropocentrism, but it also presents a view that is untenable because explaining how we know something is not the same as explaining what we know about it, which leads us to conclude that epistemology is not metaphysics. In this light, we may infer that intuition is not knowledge, regardless how epistemological it seems to be.

Nor can we accept Carnap's view that the world always needs a construct in order for it to be what it is because the world contains no system capable of doing this by itself. While not ignoring the importance of intuition, Carnap maintains that discursive reasoning is superior to intuition when assessing reality, especially when reasoning is used constructively, [17] but his description of metaphysics as being dependent upon intuition is a deliberate denunciation of metaphysics. [18] What we should conclude instead is that the world contains its own reality. The problem is not reality, but its interpretation.

Intuition is not knowledge relating to circumstance. Rather, it is the ability to recognize what a circumstance is in relationship to its context, assisted by the faculty of acting and reacting with it. In this sense, intuition has been seen as a type of proto-knowledge, but even this assumption is inaccurate. Intuition is the ability to assess what presents itself to an intuitive mind. To describe an intuitive person acting intuitively is not a redundancy, but a confirmation that a person is positioned within a relationship with someone or something else, that is, intuition concerns a juxtaposition with circumstances that a person finds himself or herself within. All of the thinkers referenced above give support to this idea. Intuition is the means to be seen, to be recognized, to be positioned as a way of dealing with the world. And this inference is applicable whether these circumstances relate to oneself, to one's relationship with other persons and/or things, or to nature. Intuition is not a totality, but a way of dealing with circumstances that are presented on a personal level. It remains fundamental because it is the means in which individuals recognize conditions that personally impact them. It is a confirmation that consciousness is distinct from and yet coexistent with self-consciousness.

Apart from conflicting views that intuition may or may not be a form of knowledge, it should be apparent that it is essential in order for communication to exist on an elementary level. Regardless of how knowledge itself is defined, intuition may be seen as a non-rational mechanism that is not epistemological, but circumstantial. Nevertheless, intuition must be defined carefully because it is a precise term. It may be defined as the description of the influence of a thing to the consciousness of a self-reflecting self when that reflection itself is compelled to recognize the influence of the thing intuited, even if that thing is not real. Accordingly, intuition projects within and without, that is, within to oneself, and without to the intuited thing, whatever it is. And the intuited thing may be an object, a subject, an image, a representation, an idea or concept, even something imagined. To identify reality absolutely through intuition is not and cannot be affirmed, however desperately we try to assert it. It will be accompanied by uncertainty. In a sense, intuition initiates a quest for truth. Because all of us are intuitive, we are all individually involved in this quest, some willingly and some reluctantly.

As indicated above, intuition signifies more than an awareness of things. It also signifies an awareness of oneself in relationship to them. Therefore, intuition has two features: an awareness of oneself because there is a self, and an awareness of oneself in relationship to things. Both features presuppose the existence of the other, that is, the self presupposes its own existence because of self-consciousness that confirms it, and it also presupposes the existence of things because they are involved in the self's selfconsciousness that is juxtaposed with everything else. There cannot be one without the other because a disconnected or solipsistic self-consciousness would not be conscious unless there is something other than itself to be conscious of. Regardless of how we define this relationship, the self and the world are not only tied together, but they must be tied together in order for the self to be a self and for the world to be a world. It cannot be otherwise, because if otherwise, there would be neither.

Intuition is more than self-consciousness because the latter is limited to what is given in order to be made conscious of. Intuition always entails something more because it contains a reverberation that implies not just self-consciousness, but a connectivity with what it. Not that the conscious subject is less important than the object, but the entire dynamic connection between them is paramount in order for intuition to be intuited. As we have said above, intuition comprises a quality of cognitive awareness moving within and without at the same time, but this feature should not be compared with a recoil that springs back as a reaction to going forward. It is not a recoil because the acknowledgment of an intuitive influence occurs simultaneously with the direct and immediate reaction to that influence. Modern psychological research has shown that intuition is multifaceted. What distinguishes humans is this contemporaneous insight and hindsight, this inward-looking and reflective phenomenon. It is the combined presence of consciousness and selfconsciousness that enables intuition to be the means to creativity. In fact, intuition is considered to be the first component of creativity, [19] a conclusion reinforced by the understanding that both intuition and creativity (in addition to imagination) are found in the right hemisphere of the brain.

Since the nature of intuition is to manifest insight and hindsight at the same time, the acknowledgment and the reactive cognition of it confer special qualities that are incisive, that is, penetrating, sharp, and clear into what is. But it may also be penetrating, sharp, and clear into what is not, since intuition may be imaginative (or abstracted), and may be confronted with a mental image that is neither perceived as real nor present. Although imagination often builds upon what is present, imaginative mental images, whether or not they are real, are a potential source of creativity, but intuition does not and cannot confer an absolute and definitive explanation of reality, even apart from the philosophical 
explanation of reality as necessary (but not contingent) existence. It is at this point that the technologization of everything is potentially harmful because if technology is applied exclusively, the effect will be an increase in abstraction that fosters virtuality in place of reality. Therefore, we might conclude that intuition is more than the recognition of a relationship between ourselves and a thing. It is more because it constitutes an essential feature of why we act the way we do, realistically or virtually. It is an essential feature of human behavior. In general, we can say that intuition is in the vanguard of all related inquiries, and it achieves this effortlessly and spontaneously. Whatever draws its attention does not guarantee a favorable effect because failure is as likely as success when acting intuitively. [20]

And success or failure is directly relevant to technological artifice. Essentially, it has a lessened basis in being, despite its rudimentary beginning. Although receiving less attention than intuition, perhaps because it is poorly understood or is thought to be less meaningful, the fact that technological artifice is an abstraction does not aid in its clarity. Any artifice, technological or otherwise, represents an openness to being because it can be present anywhere. It stands at the threshold to being, but is not being. Although it is at the point of beginning, it may generate little by way of a lasting impression.

Because technological artifice is a threshold or gateway that must be crossed in order for something to occur, like any threshold it remains an uncertainty. As Shakespeare pointed out, a threshold may foretell of dangers lurking within. [21] And dangers presuppose more than doubt, or risk, or even some kind of calamity; they suppose an emptiness between what we know and what we do not. Technological artifice is a key component to everything we do. It lies at the foundation to more than the traditional meaning of technology. It lies at the understanding of technology as a cultural phenomenon that determines human existence, incorporating the presence and meaning of human society, which as a technological phenomenon is easily observed, but difficult to explain. If technology is humanly based, what could we say about its artifice? Would we ascribe some human quality to it and still speak of it abstractly? If we associate technological artifice with any kind of method, system, or rule, then we should acknowledge that it originates from us. It is not naturally existent in the world as a worldly phenomenon. It remains an artificiality, even if we do not acknowledge or deliberately ignore its etymological roots. And yet technological artifice is evident because it is revealed in human behavior, exercised within human becoming, and manifested at the threshold of being, but remains devoid of being.

Technological artifice originates from non-being. While remaining the foundation of creativity, non-being lies at the ground of human reality. It is the well from which everything we do originates. Just as there can be no being without nonbeing, there also would be no non-being without being. Although attributed to technology, its artifice carries an auxiliary meaning. Keeping in mind that there are ideas that are joined together when in fact they should not be can help us affirm that two ideas that should be joined together are intuition and technological artifice. Because it is associated with technology, technological artifice is an affiliate of human potentiality expressed at the conjunction where 1) the ability to bring about close observation of something or the concentration of mental powers (intuition) meets 2) the ability to invent something, materially or non-materially, that might be followed by innovation (technological artifice). Even if we were to ignore our more inclusive definition of technology, we should not ignore the intuitive ability to build upon our experiences. Because intuition concerns a juxtaposition with circumstances that we find ourselves in, the circumstances that relate to technology in all its expressions are relevant to our place in the world, particularly how the world is made and how it is transformed by our being. Technological artifice exemplifies selfreflection, not necessarily rational (in an Aristotelian sense), nor necessarily essential in confirming existence (in a Cartesian sense), but a verification of existence because of an awareness of things (in a Kantian sense) and supported by an undivided continuity (in a Bergsonian sense) leading to the direct inspection of things (in a Husserlian sense) that facilitates a creative interplay in the world. By so doing, technological artifice is connected intuitively with ourselves. It is a reflection of self-consciousness (in a Sartrian sense) that is connected to a deeply directed humanly based condition that helps to define human reality.

\section{References}

[1] Dominique Bourg, L'homme artifice: le sens de la technique, [Paris]: Gallimard, 1996, p. 20, affirms that artifice and artifact must be separated.

[2] Aristotle, Posterior Analytics, bk. II, 19 (99b26-100a14), and Metaphysics, bk. XIII, 10 (1087a15-25). See Jonathan Barnes, ed., The Complete Works of Aristotle: The Revised Oxford Translation, 2 vols., Princeton: Princeton University Press, 1984, vol. I, pp. 165-66, and vol. II, p. 1718 respectively. Also see Victor Kal, On Intuition and Discursive Reasoning, Philosophia Antiqua, vol. 46, Leiden: E. J. Brill, 1988, pp. 4453, esp. pp. 46 and 48.

[3] René Descartes, "Discourse on the Method," part IV in The Philosophical Writings of Descartes, eds. [and trans.] John Cottingham, et al., 3 vols., Cambridge: Cambridge University Press, 1985-1991, vol. I (1985), p. 127.

[4] René Descartes, "Rules for the Direction of the Mind," rule 3 in ibid., Vol. I, pp. 14-15.

[5] Immanuel Kant, Critique of Pure Reason, trans. \& ed. Paul Guyer \& Allen W. Wood, The Cambridge Edition of the Works of Immanuel Kant, Cambridge: Cambridge University Press, 1998, A20/B34 (pp. 155-56) and A51/B75 (p. 193). Also see Lucy Allais, Manifest Reality: Kant's Idealism and his Realism, Oxford: Oxford University Press, 2015, pp. 158-60.

[6] For Kant, concepts must be a priori because they are needed in order for us to be able to think about objects, although his interpretation of a priori intuition is different from and not parallel to his interpretation of a priori concepts. 
[7] Henri Bergson, Matière et mémoire: Essai sur la relation du corps à l'esprit, 2nd ed., Paris: Félix Alcan, 1900, p. 202, and rendered into English in Matter and Memory, trans. Nancy Margaret Paul \& W. Scott Palmer, London: George Allen \& Unwin, 1911, pp. 238-39.

[8] Henri Bergson, Creative Evolution, trans. Arthur Mitchell, New York: Henry Holt \& Co., 1911; rpt. Lanham: University Press of America, 1983, pp. 176-77 and 182.

[9] Edmund Husserl, Logical Investigations, trans. J. N. Findlay from the Second German Edition of Logische Untersuchungen, 2 vols., London: Routledge \& Kegan Paul, 1970, vol. II (Investigation VI), sect. 45, pp. 784-86.

[10] Edmund Husserl, "Philosophy as Rigorous Science" in Phenomenology and the Crisis of Philosophy, trans. with notes and an introduction by Quentin Lauer, New York: Harper Torchbooks, 1965, pp. 110-15. Although parallel to Husserl's understanding of eidetic intuition, Heidegger's interpretation is grounded in existentiality, which is similar to Husserl's view, but with different terminology. See Martin Heidegger, Being and Time, trans. John Macquarrie \& Edward Robinson, New York: Harper \& Row, 1962, para. 31, p. 187. Furthermore, Heidegger's lectures on intuition given in 1920 that are preserved in his Phenomenology of Intuition and Expression: Theory of Philosophical Concept Formation, trans Tracy Colony, London: Continuum, 2010, describe intuition with two derivations: a priori circumstances and lived experiences. Although a priori circumstances may be accurate because they are antecedent to action, the derivation of lived experiences must be inaccurate because they do not precede intuition and are consequent to a priori.

[11] Jean-Paul Sartre, Being and Nothingness: An Essay on Phenomenological Ontology, trans. and with an introduction by Hazel E. Barnes, New York: Philosophical Library, 1956, p. 172. It cannot be affirmed that all knowledge is intuitively based. Despite a criticism of positivism and transcendentalism, Sartre's preoccupation with intuitive knowledge as the only meaningful knowledge is an exaggeration because it relegates all discursive knowledge to a subordinate position, or disregards it altogether. The claim that all knowledge is intuitive cannot be affirmed because many areas of learning, particularly science and mathematics, would be unattainable if it were true.

[12] Hilary Kornblith, "The Role of Intuition in Philosophical Inquiry: An Account with No Unnatural Ingredients," in Rethinking Intuition: The Psychology of Intuition and Its Role in Philosophical Inquiry, eds. Michael R. DePaul \& William Ramsey, Lanham: Rowman \& Littlefield, 1998, p. 134.

[13] Gilbert Simondon, On the Mode of Existence of Technical Objects, trans. Cécile Malaspina \& John Rogove, Minneapolis: Univocal Publishing, 2017, p. 235.

[14] Justus Buchler, The Concept of Method, New York: Columbia University Press, 1961, p. 85.
[15] The meaning of artifice as described in this paper should not be confused with a corporate type that has been described as a "systematized research regime" when referring to its application of business or commercial rules and regulations within a capitalistic society. See Luis Suarez-Villa, Technocapitalism: A Critical Perspective on Technological Innovation and Corporatism, Philadelphia: Temple University Press, 2009, pp. 129-32. In our sense, artifice relates to an open-ended ability to invent or devise something that may be followed by innovation. It takes an ontological approach to technology. Artifice as a systematized research regime pertains to a corporate experimentalism that uses invention or innovation for profit. It takes a methodological approach to technology.

[16] Although technological artifice is described in other publications, many of these publications emphasize its historical, not its metaphysical importance. In all honesty, we should state that it is historically inaccurate to say that "only modern technology has an artifice," even when giving support to its history, but nevertheless it is accurate to say that "only the technological age has technology accompanied by an elaborately and technically-devised framework." The difference between these two statements concerns not only that all cultures have technological artifice as a normal consequence of their being, but also that the modern age has increased its artifice to such an extent as to intensify, consolidate, heighten, and strengthen its importance. These differences should be noted. See Theodore John Rivers, "The Conception of Time and Its Relationship to Technology," Research in Philosophy and Technology, 19 (2000), 216.

[17] Rudolf Carnap, The Logical Structure of the World: Pseudoproblems in Philosophy, 2nd ed., trans. Rolf A. George, Berkeley: University of California Press, 1967, sect. 54, p. 89.

[18] Ibid., sect. 181, pp. 295-96.

[19] Tony Bastick, Intuition: How we think and act, Chichester: John Wiley \& Sons, 1982, p. 309. Although intuition is generally thought to be the first component of creativity, nonintuitive creativity may be considered if engineering projects result from systematic or algorithmic methods as discussed in G. S. [Genrikh Saulovich] Altshuller, Creativity as an Exact Science: The Theory of the Solution of Inventive Problems, trans. Anthony Williams, New York: Gordon and Breach Science Publishers, 1984, pp. 39-47, esp. pp. 42-43, that questions the reliability of experience or "natural gifts" as a suitable basis for creativity.

[20] Michael Polanyi \& Harry Prosch, Meaning, Chicago: University of Chicago Press, 1975, p. 96.

[21] William Shakespeare, King Henry the Sixth, part III, act IV, scene 7 . 